\title{
Rejection rate and mechanisms of drugs in drinking water by nanofiltration technology
}

\author{
Sijie $\mathrm{Ge}^{1,2^{+}}$, Li Feng ${ }^{1}$, Liqiu Zhang ${ }^{1^{\dagger}}$, Qiang $\mathrm{Xu}^{2+}$, Yifei Yang ${ }^{3}$, Ziyuan Wang ${ }^{2}$, Ki-Hyun $\mathrm{Kim}^{4}$ \\ ${ }^{1}$ College of Environmental Science and Engineering, Beijing Forestry University, Beijing 100083, China \\ ${ }^{2}$ Dan F. Smith Department of Chemical Engineering, Lamar University, Beaumont, TX 77710, USA \\ ${ }^{3}$ School of Municipal and Environmental Engineering, Shandong Jianzhu University, Shandong 250101, China \\ ${ }^{4}$ Department of Civil and Environmental Engineering, Hanyang University, Seoul 04763, Republic of Korea
}

\begin{abstract}
Nanofiltration (NF) technology is a membrane-based separation process, which has been pervasively used as the high-effective technology for drinking water treatment. In this study, a kind of composite polyamide NF thin film is selected to investigate the removal efficiencies and mechanisms of 14 trace drugs, which are commonly and frequently detected in the drinking water. The results show that the removal efficiencies of most drugs are quite high, indicating the NF is an effective technology to improve the quality of drinking water. The removal efficiencies of carbamazepine, acetaminophen, estradiol, antipyrine and isopropyl-antipyrine in ultrapure water are $78.8 \pm 0.8 \%, 16.4 \pm 0.5 \%, 65.4 \pm 1.8 \%$, $71.1 \pm 1.5 \%$ and $89.8 \pm 0.38 \%$, respectively. Their rejection rates increase with the increasing of their three-dimensional sizes, which indicates that the steric exclusion plays a significant role in removal of these five drugs. The adsorption of estradiol with the strongest hydrophobicity has been studied, which indicates that adsorption is not negligible in terms of removing this kind of hydrophobic neutral drugs by NF technology. The removal efficiencies of indomethacin, diclofenac, naproxen, ketoprofen, ibuprofen, clofibric acid, sulfamethoxazole, amoxicillin and bezafibrate in ultrapure water are $81 \pm 0.3 \%, 86.3 \pm 0.5 \%, 85.7 \pm 0.4 \%, 93.3 \pm 0.3 \%, 86.6 \pm 2.5 \%, 90.6 \pm 0.4 \%, 59.7 \pm 1.7 \%, 80.3 \pm 1.4 \%$ and $80 \pm$ $0.5 \%$, respectively. For these nine drugs, their rejection rates are better than the above five drugs because they are negatively charged in ultrapure water. Meanwhile, the membrane surface presents the negative charge. Therefore, both electrostatic repulsion and steric exclusion are indispensable in removing these negatively charged drugs. This study provides helpful and scientific support of a highly effective water treatment method for removing drugs pollutants from drinking water.
\end{abstract}

Keywords: Drinking water, drugs, Nanofiltration, Removal efficiency, Removal mechanism

\section{Introduction}

In recent years, it has attracted the increasing attention on the presence of drugs and their remains in the aquatic environment [1-6]. A wide range of drugs are frequently detected in the surface and ground water due to their incomplete assimilation by human and animals as well as poor removal efficiencies in wastewater treatment plants [7-8]. The long-term exposure of drugs may lead to potential threats to human health and water ecological security [9-11]. Therefore, the study on the high-effective removal techniques of drugs from water is an urgent need. In recent decades, nanofiltration (NF), a low pressure-driven membrane process, has been gaining much attention due to its high rejection rates to many low molecule weight organic pollutants [12-15]. NF was a costly technology due to the short life cycle, easily fouling and high operation cost in the past. However, with the development of research and the improved manufacturing technology, the cost of NF has decreased significantly, which makes NF become a promising application in water treatment [15-19]. For the quality and safety of supply drinking water, it is expected that NF will be widely employed into drinking water treatment in the near future.

Recently, some researchers investigated the removal performance of drugs by NF technology [20-25]. Three major drug removal mechanisms are proposed, including steric exclusion, electrostatic repulsion and adsorption. Steric exclusion is considered as one of the removal mechanism in removing all kinds of drugs, especially for drugs having no charge, which are called as neutral
This is an Open Access article distributed under the terms of the Creative Commons Attribution Non-Commercial License (http://creativecommons.org/licenses/by-nc/3.0/) which permits unrestricted non-commercial use, distribution, and reproduction in any medium, provided the original work is properly cited.
Received December 24, 2016 Accepted March 22, 2017

${ }^{\dagger}$ Corresponding author

Email: sge@lamar.edu / zhangliqiu@163.com / qiang.xu@lamar.edu Tel: +1-409-880-7818

Copyright (C) 2017 Korean Society of Environmental Engineers 
drugs. The molecular weight cut-off (MWCO) of NF and the molecular weight of drug are employed to evaluate the removal efficiency. However, it is inadequate and inaccurate to adopt the MWCO to evaluate the removal performance of $\mathrm{NF}$ as well as use the molar weight to weigh the size of drug molecule [20]. In addition, increasing environmental awareness coupled with more stringent regulation standards has triggered various industries to challenge themselves in seeking appropriate wastewater treatment technologies [21]. Note that the removal efficiency is not consistent with the MWCO and drug molecular weight in NF. Regarding this, this paper is focused on the influence of the molecular dimensions of three-dimensional structure on the rejection of non-absorption neutral drugs by NF [22-23]. The removal mechanism can be further elaborated instead of only focus on the NF MWCO and drug molecular weight. Besides, hydrophobic interaction is also noticeable between some neutral drugs and NF in the experiments. However, hydrophobic interaction may cause the different consequences, which need more researchers' efforts to investigate [24-26]. On the one hand, hydrophobic interaction causes the membrane fouling and makes the membrane pore size become smaller, which can increase the removal efficiency. On the other hand, the hydrophobicity makes the drug absorbed onto and partition into membrane surface, which will facilitate the drug diffusion to go through the NF membrane.

The previous research showed that most of NF membranes were negatively charged at the condition of neutral or alkaline solution due to the dissociation of functional groups (e.g., carboxylic acid groups) on the membrane surface [27]. The amount of negative charges on membrane surface increases with the increase of the $\mathrm{pH}$ value of the solution due to the acid group on membrane surface is gradually dissociated. Thus, the amount of negative charges on membrane surface would be changed with the $\mathrm{pH}$ value of the solution [20-23, 28-29]. Note that drugs containing acid functional groups (e.g., the carboxylic group, phenolic hydroxyl group and et al.) have several different forms based on the $\mathrm{pH}$ value of feed solution. These drugs are regarded as the negatively charged drugs. Usually, negatively charged drugs exist in two kinds of specifications (negative ionic and neutral forms) when the dissociation constant of the drug (pKa) is smaller than the $\mathrm{pH}$ value of solution. Therefore, the electrostatic repulsion can occur between negatively charged drugs and negative $\mathrm{NF}$ membrane in certain solution conditions. As known, the removal mechanism for negatively charged drugs is completely different from that of the neutral drugs. Thereby, the $\mathrm{pH}$ value of the solution plays a significant role in removing charged drugs by NF. Some studies have reported that the role of electrostatic repulsion is very crucial in removing the charged organic solutes [20-22, 27-29]. Based on our literature survey, the role of steric exclusion for removal the charged organic solutes is still not clear. So, it is interesting to know the removal mechanisms for the charged drugs. The cost of NF membrane water treatment plant varies and is dependent on the production capacity, type of treatment involved, design criteria, characteristics of land and building, etc. [30-31]. NF technology will have the tremendous market requirement in the near future with the increase of water quality standard and the decrease of NF cost. The rejection rate for NF membrane are the most important aspect for the design of membrane filtration plant as it is a direct measure of productivity, operating pressure (energy requirements) and amount of membrane required (membrane area) [32]. Hence, studying the rejection rate for drugs in the drinking water is capable to provide acceptable economic estimation for the water treatment by NF membrane.

Fourteen drugs (i.e. carbamazepine, indomethacin, diclofenac, antipyrine, naproxen, ketoprofen, ibuprofen, clofibric acid, acetaminophen, sulfamethoxazole, amoxicillin, estradiol, bezafibrate and isopropyl-antipyrine) were selected as the objective water pollutants due to their high exposure levels in water environment. These drugs also stand for a broad range of physical and chemical properties (i.e., size, pKa, hydrophilicity, and water solubility) and their different rejection rates are expected to achieve by the NF. In summary, this paper will employ a popular commercial $\mathrm{NF}$ membrane to remove those selected fourteen drugs and the removal efficiency and mechanism will be systematically investigated. This study will provide the helpful and scientific supports for the development of high-effective water treatment technology (NF) in the application of removing drug pollutants from water.

\section{Materials and Methods}

\subsection{Membrane and Chemicals}

A composite NF membrane thin film named NF-270 was selected in this study and the properties of NF-270 are presented in Table 1 [29]. The physic-chemical properties of the selected 14 drugs are summarized in Table 2. All of the drugs were purchased from Sigma-Aldrich. The purities of all drugs were more than $98 \%$. The stock solution was prepared by dissolving each drug $20 \mathrm{mg} / \mathrm{L}$ in methanol solvent and stored at $-4^{\circ} \mathrm{C}[24,29]$. All chemicals were at least reagent grade. It is worth pointing out that based on the drugs distribution curve, five drugs (acetaminophen, carbamazepine, antipyrine, isopropyl-antipyrine and estradiol) are neutrally non-charged solutes and the other nine drugs are negatively charged solutes while the solution is ultra pure water (i.e. the $\mathrm{pH}$ value is about 7.01).

Table 1. The Properties of NF Membrane Used in the Experiments

\begin{tabular}{|c|c|c|c|c|c|}
\hline Material & Pure water permeability $\left(\mathrm{L} / \mathrm{m}^{2} / \mathrm{h}\right)$ & $\mathrm{MgSO}_{4}$ rejection(\%) ${ }^{\mathrm{a}}$ & $\mathrm{NaCl}$ rejection(\%) ${ }^{\mathrm{b}}$ & Contact angle $\left({ }^{\circ}\right)^{\mathrm{c}}$ & Applied pH range \\
\hline polyamide & $77 \pm 3$ & 99.38 & 51.71 & $20.6 \pm 2$ & $3.0-11.0$ \\
\hline
\end{tabular}

a) Experimental conditions: $5 \mathrm{mmol} / \mathrm{L} \mathrm{MgSO}_{4}$ in ultra pure water, 5 bar, $\mathrm{pH}=7.00 ; \mathrm{MgSO}_{4}$ rejection based on Flame Atomic Absorption Spectrometry measurement (FAAS).

b) Experimental conditions: $10 \mathrm{mmol} / \mathrm{L} \mathrm{NaCl}$ in ultra pure water, $5 \mathrm{bar}, \mathrm{pH}=7.00$; $\mathrm{NaCl}$ rejection based on FAAS measurement.

c) The contact angle was measured by the static captive bubble method. 
Table 2. Physic-chemical Properties of Selected Fourteen Drugs (n.d.: not determined)

\begin{tabular}{|c|c|c|c|c|c|c|c|}
\hline Drug & $\begin{array}{c}\text { MW } \\
\text { (g/mol) }\end{array}$ & $\log k_{\text {ow }}$ & pKa & $\begin{array}{c}\text { chemical } \\
\text { formula }\end{array}$ & structure & $\begin{array}{l}\text { Water solubility } \\
(\mathrm{mg} / \mathrm{L})\end{array}$ & $\begin{array}{c}\text { Charge at } \\
\text { pH } 7.00\end{array}$ \\
\hline Acetaminophen & 151.16 & 9.5 & 0.46 & $\mathrm{C}_{8} \mathrm{H}_{9} \mathrm{NO}_{2}$ & & $1.4 \times 10^{4}$ & neutral \\
\hline Antipyrine & 188.22 & 1.5 & 0.38 & $\mathrm{C}_{11} \mathrm{H}_{12} \mathrm{~N}_{2} \mathrm{O}$ & & $1.0 \times 10^{6}$ & neutral \\
\hline Carbamazepine & 236.27 & 13.9 & 2.45 & $\mathrm{C}_{15} \mathrm{H}_{12} \mathrm{~N}_{2} \mathrm{O}$ & & 17.66 & neutral \\
\hline Estradiol & 272.39 & 10.7 & 4.01 & $\mathrm{C}_{18} \mathrm{H}_{24} \mathrm{O}_{2}$ & & 81.97 & neutral \\
\hline Isopropyl-antipyrine & 230.31 & n.d. & 1.94 & $\mathrm{C}_{14} \mathrm{H}_{18} \mathrm{~N}_{2} \mathrm{O}$ & & n.d. & neutral \\
\hline Indomethacin & 357.79 & 4.5 & 4.27 & $\mathrm{C}_{19} \mathrm{H}_{16} \mathrm{ClNO}_{4}$ & & 0.94 & $\begin{array}{c}\text { negatively } \\
\text { charged }\end{array}$ \\
\hline Diclofenac & 318.13 & 4.15 & 4.51 & $\mathrm{C}_{14} \mathrm{H}_{10} \mathrm{Cl}_{2} \mathrm{NaO}_{2}$ & & 2.37 & $\begin{array}{c}\text { negatively } \\
\text { charged }\end{array}$ \\
\hline Naproxen & 230.26 & 4.15 & 3.18 & $\mathrm{C}_{14} \mathrm{H}_{14} \mathrm{O}_{3}$ & & 15.9 & $\begin{array}{c}\text { negatively } \\
\text { charged }\end{array}$ \\
\hline Ketoprofen & 254.28 & 4.45 & 3.12 & $\mathrm{C}_{16} \mathrm{H}_{14} \mathrm{O}_{3}$ & & 51 & $\begin{array}{c}\text { negatively } \\
\text { charged }\end{array}$ \\
\hline Ibuprofen & 206.28 & 4.91 & 3.97 & $\mathrm{C}_{13} \mathrm{H}_{18} \mathrm{O}_{2}$ & & 21 & $\begin{array}{c}\text { negatively } \\
\text { charged }\end{array}$ \\
\hline Clofibric acid & 214.65 & 3.0 & 2.57 & $\mathrm{C}_{10} \mathrm{H}_{11} \mathrm{ClO}_{3}$ & & 582.5 & $\begin{array}{c}\text { negatively } \\
\text { charged }\end{array}$ \\
\hline Sulfamethoxazole & 253.27 & $5.7,1.8$ & 0.89 & $\mathrm{C}_{10} \mathrm{H}_{11} \mathrm{~N}_{3} \mathrm{O}_{3} \mathrm{~S}$ & & 3,942 & $\begin{array}{c}\text { negatively } \\
\text { charged }\end{array}$ \\
\hline Amoxicillin & 365.41 & 2.7 & 0.87 & $\mathrm{C}_{16} \mathrm{H}_{19} \mathrm{~N}_{3} \mathrm{O}_{5} \mathrm{~S}$ & & n.d. & $\begin{array}{c}\text { negatively } \\
\text { charged }\end{array}$ \\
\hline Bezafibrate & 361.82 & 3.44 & 4.25 & $\mathrm{C}_{19} \mathrm{H}_{20} \mathrm{ClNO}_{4}$ & & 15 & $\begin{array}{c}\text { negatively } \\
\text { charged }\end{array}$ \\
\hline
\end{tabular}


In this study, we employed the parameter of three-dimensional structure to describe the molecular dimensions of non-absorption neutral drugs, so that steric exclusion effect on the removal efficiency of this kind of drug can be validated in more details. The molecular length was defined as the distance between the two most distant atoms of a particular molecule [26]. The average dimension was employed and defined as the geometric mean of length, width and depth, so that the molecular size can be fully evaluated from the three different dimensions. This mathematical equation about the relation of the average dimension, length, width and depth is shown as follows.

$$
D=(A \times B \times C)^{1 / 3}
$$

where $D, A, B$ and $C$ are the average dimension, length, width and depth, nm, respectively.

\subsection{Filtration Protocol and Equipment}

In all filtration experiments, the basic solution contained $\mathrm{NaCl}$ (10 mmol/L) and phosphate buffer $(5 \mathrm{mmol} / \mathrm{L})$. The concentration of drugs was $200 \mathrm{ug} / \mathrm{L}$. The $\mathrm{pH}$ of the solution was achieved by adjusting with addition of either sodium hydroxide $(0.1 \mathrm{~mol} / \mathrm{L})$ or hydrochloric acid $(0.1 \mathrm{~mol} / \mathrm{L})$ solution. Ultra pure water was used for the preparation of all stock solutions and filtration experiments.

A laboratory-scale, cross-flow membrane filtration test unit is consisted of feed tank ( $1 \mathrm{~L})$, diaphragm pump, flow meter and membrane cell (shown in Fig. 1). Temperature of the feed tank was maintained at $25 \pm 0.5^{\circ} \mathrm{C}$ by a thermostat (DC-0515, made in China). All experiments were carried out in a circulation mode, with both permeate and concentrate recycling back to the feed tank so as to hold the constant feed concentration. To estimate the removal efficiencies of $\mathrm{NF}$ on 14 drugs, the removal experiments were firstly performed with ultra pure water as a reference. For each experiment, a new membrane sheet with the effective membrane area of $32 \mathrm{~cm}^{2}$ was used. Each experiment was conducted in 5 bar trans-membrane pressures. In contrast, a control experiment was performed without the NF membrane sheet, which indicated that the amount of drugs adsorbed on the experimental equipment was negligible based on the material balance. Prior to each experiment, the membrane sheet was soaked in ultra pure water for at least $48 \mathrm{~h}$ in order to remove impurities from the manufacturing process. Approximately, $0.5 \mathrm{~mL}$ of feed and permeate samples were analyzed three times in parallel. The drug

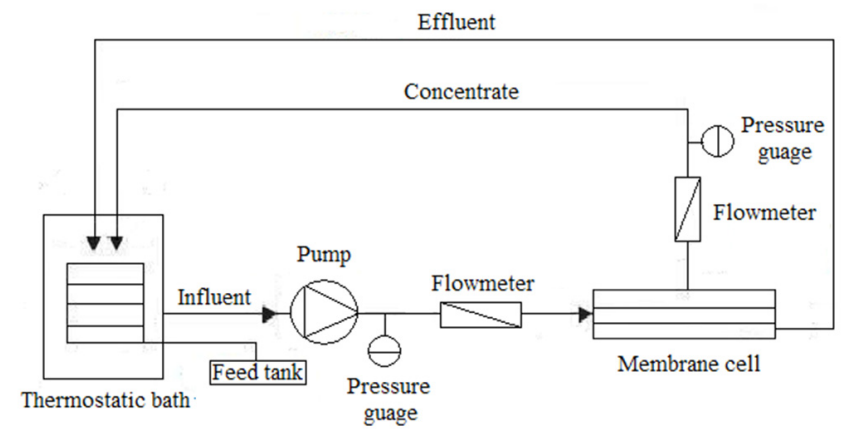

Fig. 1. Experimental equipment of NF membrane. concentrations of the influent and effluent were basically steady corresponding to a constant rejection over time. Rejection of drugs was calculated according to Eq. (2)

$$
R(\%)=\left(1-C_{p} / C_{f}\right) \times 100 \%
$$

where $R$ is the rejection rate (\%), $C_{p}$ and $C_{f}$ are the drug concentrations in the permeate and feed tank, ug/L, respectively.

\subsection{Analytical Methods}

The concentrations of drugs were analyzed by high performance liquid chromatography (HPLC, Agilent 1260, USA) equipped with a UV detector and a Poroshell 120 EC-C18 column $(4.6 \times 50 \mathrm{~mm}$, $2.7 \mathrm{um}$ ). The detection wavelengths of carbamazepine, indomethacin, diclofenac, antipyrine, naproxen, ketoprofen, ibuprofen, clofibric acid, acetaminophen, sulfamethoxazole, amoxicillin, estradiol, bezafibrate and isopropyl-antipyrine were 285, 265, 280, 242, 231, 256, 219, 228, 246, 268, 230, 279, 228 and $266 \mathrm{~nm}$, respectively. Acetonitrile, methanol and ultra pure water (60:30:10, v:v) were used as the mobile phase, delivered at a constant flow rate of 0.5 $\mathrm{mL} / \mathrm{min}$. The injection volume was $10 \mathrm{uL}$. The value of $\mathrm{pH}$ was obtained by using a Sartorius Professional $\mathrm{pH}$ meter (PP-50). The lower limit of detecting ability for all drugs was approximately 5 $\mathrm{ug} / \mathrm{L}$. The relative coefficients $\left(\mathrm{R}^{2}\right)$ of standard curves reached 0.999 .

\section{Results and Discussion}

\subsection{Rejection Fourteen Different Types of Drugs by NF Technology}

3.1.1. The removal efficiencies of fourteen drugs by NF technology Fig. 2 shows that NF achieves very high rejection for the most of 14 drugs and the rejection rates of nine negatively charged drugs are higher than those of the neutral drugs. The highest rejection rate by $\mathrm{NF}$ is found for ketoprofen (93.3 $\pm 0.3 \%$ ). However, acetaminophen is removed with relatively poor efficiency (16.4 $\pm 0.5 \%$ ). It is obvious that the rejection rates of neutral drugs are lower in comparison to the negatively charged drugs based on the Fig. 2. As we know, the rejection rates of NF are quite high for most of pollutants even for the small molecules. However, the rejection rates of fourteen drugs are definitely different ranging from the lowest $(16.4 \pm 0.5 \%)$ to the highest $(93.3 \pm 0.3 \%)$. Sieving exclusion is an important removal mechanism in the process of membrane separation. Compared to neutral drugs, the relatively higher degree of rejection of the negatively charged drugs may due to the electrostatic repulsion aside from the steric exclusion mechanism. Thus, it is worth further investigating the reasons of considerable difference in these drugs. Therefore, the selected 14 drugs are divided into two categories (i.e., neutral drugs and negatively charged drugs) based on the drug speciation distribution curve. It is also noted that the material balance is performed to investigate the amount of drugs absorbed on the membrane shell after the end of separation experiment. $60.16 \mathrm{ug}$ of estradiol is absorbed on the membrane shell, whereas the absorption amount of other 13 drugs are less than $10 \mathrm{ug}$. The absorption effect of the estradiol will be specially studied in details in section 3.4. 


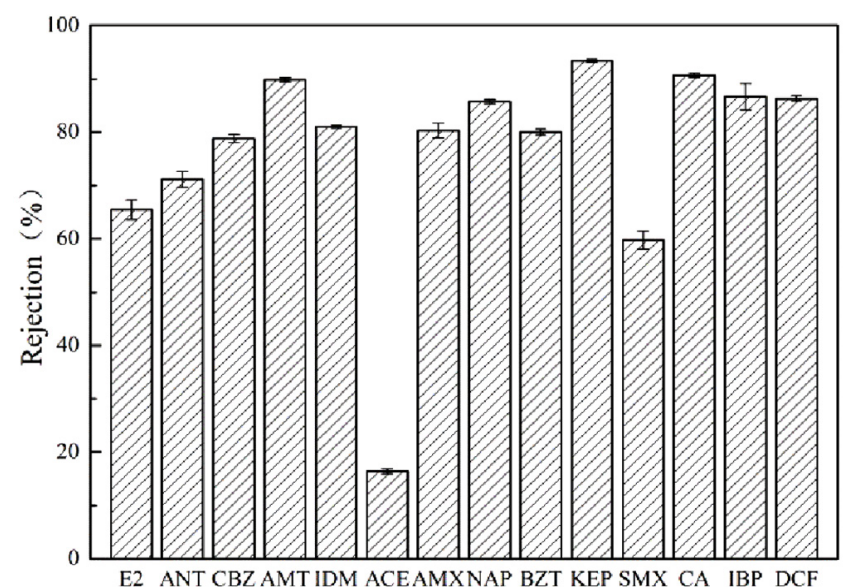

Fig. 2. The removal efficiencies of the selected fourteen drugs by NF.

\subsubsection{Molecule weight effect on the drug rejection}

It is obvious that the relationship between the rejection and the molecule weight of 14 drugs is not linear based on the Fig. 3. The linear correlation coefficient $\left(\mathrm{R}^{2}\right)$ is only 0.1499 . It is prominent that although neutral carbamazepine has higher molecular weight than that of the neutral isopropyl-antipyrine (shown in Table 2), the rejection rate of carbamazepine is obviously lower than that of isopropyl-antipyrine. Thus, it seems that the rejection rate of drug is irrelative with their molecule weights. The molecular weight cut-off of NF membrane is about $300 \mathrm{~g} / \mathrm{mol}$. However, the rejection rates of some drugs whose molecule weight are larger than $300 \mathrm{~g} / \mathrm{mol}$ are still below $90 \%$. Thus, MWCO cannot accurately predict the removal efficiencies of drugs by NF membrane [23-24, 33-34]. The lowest rejection of acetaminophen among these drugs might be explained by two causes as follows. On the one hand, there is no electrostatic interaction between the neutral non-charged acetaminophen molecule and the membrane surface. It seems that only the steric exclusion can play a part (have effect or play an important role) in this kind of drugs rejection. On the other hand, it has the greater affinity towards water due to the higher water solubility (shown in Table 2), so that it can easily across the membrane structure into the permeate.



Fig. 3. The removal efficiencies of fourteen drugs vs their molar weights.

\subsection{The Removal Mechanisms of the Neutral Drugs}

\subsubsection{Influence of $\mathrm{pH}$ on neutral drugs rejection}

The rejection rates of four neutral drugs basically keep constant while $\mathrm{pH}$ value ranges from acidic condition (3.48) to alkaline condition (10.01) unlike the trend of acetaminophen shown in Fig. 4. As the $\mathrm{pH}$ value below 7.50, acetaminophen, carbamazepine, antipyrine and isopropyl-antipyrine mainly exist as neutral species. However, acetaminophen is negatively charged when the $\mathrm{pH}$ value above 7.50, while the other three drugs are still neutral substance. The amount of charges on the membrane surface is strengthened as the increase of the $\mathrm{pH}$ value. However, the rejection of carbamazepine, antipyrine and isopropyl-antipyrine still keep constant. Thus, the removal mechanism of neutral drugs may only attribute to the sieving exclusion other than the electrostatic interaction. It is noted that at $\mathrm{pH}=10.01$, the rejection rate of acetaminophen significantly increases to $73.7 \%$. The reason is that phenolic group of acetaminophen can be deprotonated resulting in a more negatively charged, and then the electrostatic repulsion dominates to remove acetaminophen. The steric exclusion and electrostatic repulsion simultaneously exist in the alkalic solution, so that the rejection rate of acetaminophen can be remarkably increased by $57.3 \%$ comparing to the $16.4 \%$ rejection rate without the electrostatic repulsion. It seems that the electrostatic repulsion has a stronger impact on the rejection rate of acetaminophen than steric exclusion. Therefore, the rejection rate of acetaminophen can be efficiently improved by changing the solution's $\mathrm{pH}$ into alkalic condition.



Fig. 4. Rejection of neutral drugs by the NF membrane as the solution $\mathrm{pH}$ value.

3.2.2. Effect of molecular dimensions on the rejections of drugs Previous studies have shown that the NF membrane has an average pore radius of $0.42 \mathrm{~nm}$ [29]. As discussed in Section 3.2.1, molecular weight cannot be used to stand for the precise molecular dimensions and predict the drug rejection rate. The average dimension, molecular length, width and depth are employed to describe the molecular dimensions of drugs. The molecular dimensions of the three neutral 
Table 3. The Relationship between Molecular Dimensions and the Removal Efficiencies of Acetaminophen, Antipyrine and Carbamazepine

\begin{tabular}{cccccccc}
\hline Drug & $\begin{array}{c}\mathbf{R} \\
\mathbf{( \% )}\end{array}$ & $\begin{array}{c}\text { Molecule weight } \\
\text { (g/mol) }\end{array}$ & $\begin{array}{c}\text { AFM } \\
\mathbf{( n m )}\end{array}$ & $\begin{array}{c}\text { molecular depth } \\
\text { (nm) }\end{array}$ & $\begin{array}{c}\text { molecular width molecular length average dimension } \\
\text { (nm) }\end{array}$ & $\begin{array}{c}\text { (nm) } \\
(\mathbf{n m})\end{array}$ \\
\hline acetaminophen & 16.4 & 151.2 & 105.7 & 0.42 & 0.68 & 1.14 & 0.53 \\
antipyrine & 71.1 & 188.2 & 66.6 & 0.56 & 0.78 & 1.17 & 0.66 \\
carbamazepine & 78.8 & 236.3 & 84.5 & 0.58 & 0.92 & 1.00 & 0.73 \\
\hline
\end{tabular}

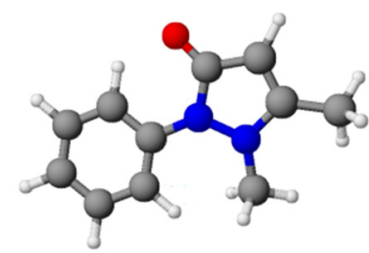

Antipyrine

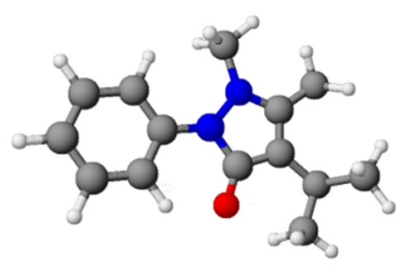

Isopropyl-antipyrine
Fig. 5. Three-dimensional models of antipyrine and isopropyl-antipyrine.

drugs are summarized in Table 3. It can be seen that the rejection rates of neutral drugs by NF membrane vary from $16.4 \%$ to $89.8 \%$. The rejection rates of neutral drugs appeared dramatically in accordance with the molecular length, width, depth and average dimension. This is the reason that the removal efficiencies of neutral drugs increase with the molecular dimensions. This phenomenon might be attributed to their removal mechanism mainly determined by steric exclusion. It seems that the rejection rates of neutral non-adsorptive drugs increase with the average dimension. In addition, the three-dimensional models of antipyrine and isopropyl-antipyrine are presented in Fig. 5. It is apparent to see that the additional functional group of an isopropyl exists in isopropyl-antipyrine molecule structure other than the structure of antipyrine molecule, which indicates that the molecular dimensions of isopropyl-antipyrine are larger than antipyrine. Therefore, the rejection of isopropyl-antipyrine is higher than that of antipyrine attributed to the steric exclusion.

\subsection{Removal Mechanisms of Negatively Charged Drugs by NF Membrane}

Naproxen, bezafibrate and ibuprofen are employed to study the removal mechanisams of negatively charged drugs in this section due to the apparent different physico-chemical properties with the same special functional group of carboxyl acid group. The properties of these three drugs are expected to be sensitive to the $\mathrm{pH}$ value due the carboxyl acid group. The speciation distribution curves of three drugs are given in the Fig. 6 .

The surface chemical characteristics of NF membrane are determined by the polyamide layer. This polyamide layer contains both carboxylic and amine functional groups that can ionize in the aqueous solution [27]. The degree that NF membrane surface has been negatively charged can be clearly reflected and characterized by using the rejection rates of sodium chloride at the different $\mathrm{pH}$ values shown in Fig. 7. As seen in Fig. 7, the rejection rate of sodium chloride increases from $51.71 \%$ to $99.38 \%$, which means the surface of NF membrane has been negatively charged
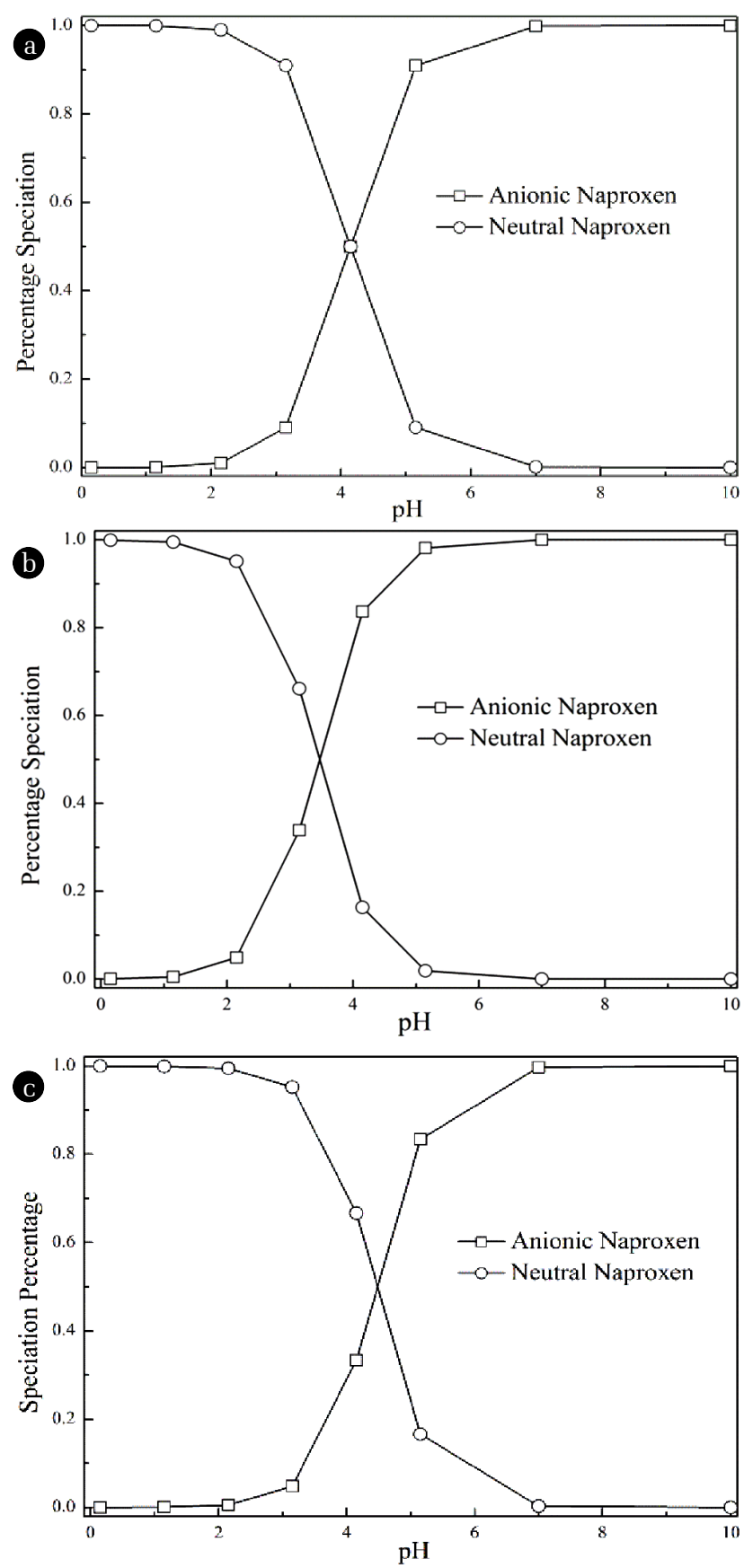

Fig. 6. Speciation for (a) naproxen; (b) bezafibrate; and (c) ibuprofen as a function of $\mathrm{pH}$, calculated based on their pKa values. 


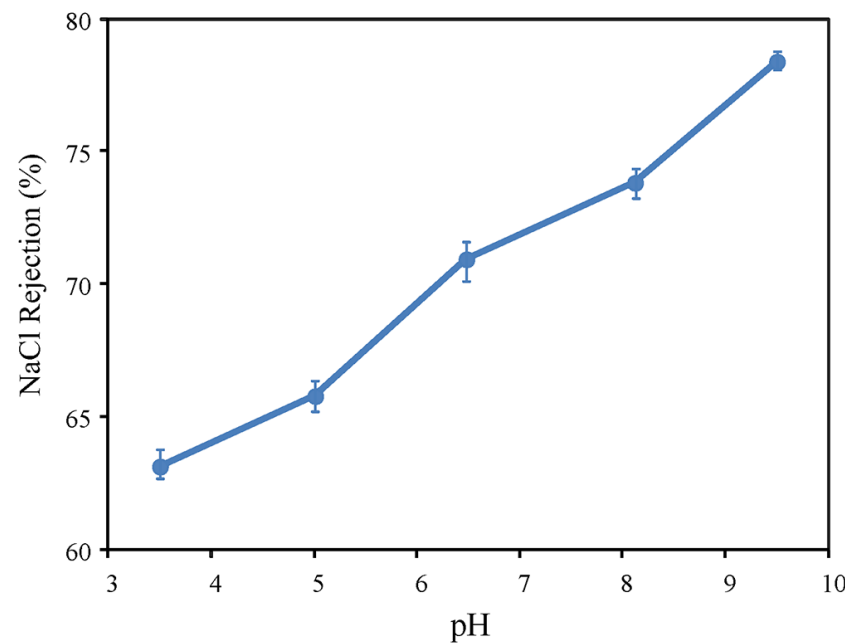

Fig. 7. The rejection rate of sodium chloride in the NF membrane as a function of the solution $\mathrm{pH}$.

and the degree that the NF membrane surface has been negatively charged increases along with $\mathrm{pH}$ value.

Fig. 8 shows the influence of solution's $\mathrm{pH}$ on the rejection of three negatively charged drugs. It is observed that for NF membrane, as the $\mathrm{pH}$ of the solution increased, the rejection of drugs is also increased. This is because the $\mathrm{pH}$ value determines the species distribution of drugs in the solution and changes the degree that NF membrane surface has been negatively charged. The percentage of negatively charged drugs increases as the $\mathrm{pH}$ value of the solution. Thus, the electrostatic repulsion force between drugs and membrane has been gradually increased, resulting in the increase of the rejection rates obviously. It is noted that the rejection rates of naproxen and ibuprofen, in contrast to that of bezafibrate, are significantly impacted by $\mathrm{pH}$ value of the solution. At $\mathrm{pH}=3.48$, the rejection rates of naproxen and ibuprofen are $25.7 \%$ and $11.7 \%$, respectively. Based on the speciation distribution curves, it can be seen that at $\mathrm{pH}$ above 5.53, the naproxen and ibuprofen are almost completely dissociated, indicating both of them exists in the form of the negatively charged substance. Thus, the rejection rates of naproxen and ibuprofen are sharply increased to $94 \%$ as the $\mathrm{pH}$ of the solution is higher than 5.53 , due to the increase of electrostatic repulsion force between the drugs and the negatively charged membrane. When the $\mathrm{pH}$ is lower than 3.48 , the amount of negatively charged of membrane surface is decreased, and the dissociated and negatively charged drugs regain the proton, and then is changed to the neutral substance. Therefore, the elimination of charge repulsion between drugs and membrane is not beneficial to the removal efficiencies of drugs. In this situation, the rejection rates of the drugs are only determined by steric exclusion and hydrophobic interactions between the drugs and the membrane. Besides, the rejection of bezafibrate is also influenced by electrostatic repulsion between the membrane and drugs. However, the rejection rate of bezafibrate increases from $75 \%$ to $90 \%$ as the $\mathrm{pH}$ value ranges from 3.48 to 9.97 . Although the degree that membrane surface has been negatively charged sharply increases when the $\mathrm{pH}$ value changes from acidic into alkaline condition, the increment of rejection rate of bezafibrate is smaller



Fig. 8. Effect of $\mathrm{pH}$ of the solution on the rejection rates of naproxen, bezafibrate and ibuprofen.

than those of naproxen and ibuprofen. It seems that the electrostatic repulsion mechanism is more dominated in removal of naproxen and ibuprofen than the removal of bezafibrate.

In contrast to the solution with the lower $\mathrm{pH}$ value $(<5.53)$, the higher rejection rates of naproxen, bezafibrate and ibuprofen by the NF membrane are observed in the solution with the $\mathrm{pH}$ value ranging from 5.53 to 9.97 . It is noted that steric exclusion may also contribute to the removal mechanism of these three negatively charged drugs. Generally speaking, electrostatic repulsion and steric exclusion are simultaneously responsible for the removal of negatively charged drugs by NF membrane. Therefore, both electrostatic repulsion and steric exclusion are dominated the rejection of negatively charged drugs by $\mathrm{NF}$ membrane.

\subsection{Adsorption of NF Membrane for Estradiol (E2)}

The contact angle of clean NF was measured as $20.6^{\circ}$, which shows that the clean NF had contact angle within the range of the hydrophilic material (Vogler, 1999). Adsorption has also an important influence on the rejection of hydrophobic drugs by using NF treatment. The hydrophobic drug can be easily adsorbed onto the NF membrane surface and then dissolved and permeated into the membrane. Therefore, hydrophobic interaction plays a key role between the drug solute and the membrane phase, and often results in a lower rejection rate [8]. Estradiol, which is a hydrophobic neutral solute with the highest $\operatorname{logk}_{\text {ow }}$ among the selected fourteen drugs, is employed to study the absorption effect during the NF membrane separation. The result from our previous experimental data in ultra pure water showed that adsorption accounted for $30 \%$ in the rejection of the estradiol based on the material balance. There is no electrostatic interaction between the estradiol and $\mathrm{NF}$ membrane at the condition of $\mathrm{pH}=7.01$. The rejection of the estradiol only can be determined by steric exclusion and adsorption between the estradiol and the NF membrane.

During the separation process of removing estradiol, the two eminent phenomena are observed shown in the Fig. 9. One is that the concentration of estradiol in the influent decreases due 




Fig. 9. Variation of estradiol's concentration in both the effluent and influent via time.

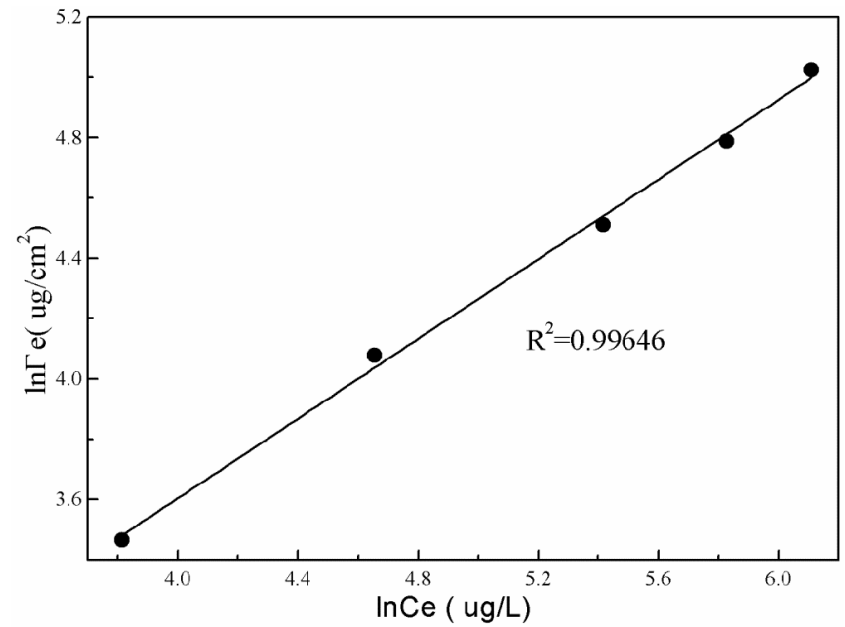

Fig. 10. Freundlich adsorption isotherms of the amount of estradiol in the unit of membrane area with the concentration of estradiol.

to adsorption on the membrane surface shown in Fig. 9. On the contrary, the concentration of estradiol in the permeate increases gradually as the amount of estradiol penetrated the membrane phase after the absorption balance. Hydrogen bonds are formed between estradiol molecule and the surface of polyamide membrane that make the estradiol easily to approach the membrane surface and then result in the higher rejection rate during the initial stage of membrane separation. During the initial stage, estradiol molecules in effluent are continuously adsorbed on the surface of the membrane until adsorption equilibrium is reached. Given that the cross flow way of NF separation, the direction of stream is parallel to the direction of membrane surface, which is adverse to build the adsorption equilibrium comparing to dead-end filtration way. Therefore, adsorption equilibrium can be built after 40 min filtration. After the adsorption equilibrium has been built, the amount of estradiol that is released into the permeate can reach the maximum so that the concentration of the estradiol in the permeate can also reach the maximum, which means the removal efficiency of estradiol can keep constant. Therefore, the adsorption can contribute to enhance the rejection rate of estradiol in the initial stage. It is noted that estradiol would eventually be removed by the NF membrane through exclusion effect other than adsoption effect. Besides, membrane pores are decreased due to adsorption effect, which forces estradiol to deposite into the membrane, so that the exclusion effect can be strengthened. In the meanwhile, the amount of estradiol in membrane phase increases as the increase of the concentration of estradiol in the feed tank. Results about batch adsorption tests performed in NF membrane shell are shown in Fig. 10. This adsorption behavior between estradiol and NF membrane matches well $\left(\mathrm{R}^{2}=0.99646\right)$ with the following Freundlich adsorption isothermal model:

$$
\ln (\Gamma e)=(1 / n) \times \ln (C e)+\ln K
$$

where $K$ and $1 / n$ represent adsorption capacity and adsorption capacity index, respectively. Гe represents the amount of estradiol in the unit of membrane area $\left(\mathrm{ug} / \mathrm{cm}^{2}\right)$. Ce represents the concentration of estradiol in the feed tank.

\section{Conclusions}

$\mathrm{NF}$ membrane has very high rejections for the most of fourteen drugs due to the different size, pKa and charge. Thus, the NF can be a high-effective technology to improve the quality and safety of drinking water. The NF membrane in removal of different types of drugs exhibits the different removal mechanisms. And the experiment results show that the rejection rates of nine negatively charged drugs are commonly higher than those of the neutral drugs. For neutral drugs, the steric exclusion is a major removal mechanism and the rejection rate remarkably increases with the increase of 3-D structure size. For negatively charged drugs, both electrostatic repulsion and the steric exclusion are the major removal mechanisms. And electrostatic repulsion has stronger influence on the rejection of negatively charged drugs in contrast to the steric exclusion. The rejection rate of acetaminophen, which is one of the neutral drugs, can be improved by adjusting the solution into the alkalinic condition because electrostatic repulsion also works on removing acetaminophen other than steric exclusion. It is worth to point out that the adsorption effect cannot be neglected in removing the $\mathrm{E}_{2}$. The rejection rate of $E_{2}$ can be strengthened by the adsorption effect. In summary, the steric exclusion, electrostatic repulsion and adsorption effect are simultaneously existed in the removing drugs by using NF membrane separation.

\section{Acknowledgements}

This research was supported by the Special Fund for Environmental Protection Research in the Public Interest (No.201209048), Special S\&T Project on Treatment and Control of Water Pollution (No. 2013ZX07201007-003) and National Science Foundation of China (No. 51178046). Also, thanks for the Graduate Scholarship of Lamar University and Beijing Key Lab for Source Control Technology of Water Pollution. 


\section{References}

1. Mompelat S, Le Bot B, Thomas O. Occurrence and fate of pharmaceutical products and by-products, from resource to drinking water. Environ. Int. 2009;35:803-814.

2. Díaz-Cruz MS, Barceló D. Trace organic chemicals contamination in ground water recharge. Chemosphere 2008;72: 333-342.

3. Barnes KK, Kolpin DW, Furlong ET, Zaugg SD, Meyer MT, Barber LB. A national reconnaissance of pharmaceuticals and other organic wastewater contaminants in the United States - I) Groundwater. Sci. Total Environ. 2008;402:192-200.

4. Focazio MJ, Kolpin DW, Barnes KK, et al. A national reconnaissance for pharmaceuticals and other organic wastewater contaminants in the United States - II) Untreated drinking water sources. Sci. Total Environ. 2008;402:201-216.

5. Schaider LA, Rudel RA, Ackerman JM, Dunagan SC, Brody JG. Pharmaceuticals, perfluorosurfactants, and other organic wastewater compounds in public drinking water wells in a shallow sand and gravel aquifer. Sci. Total Environ. 2014;468:384-393.

6. Padhye LP, Yao H, Kung'u FT, Huang CH. Year-long evaluation on the occurrence and fate of pharmaceuticals, personal care products, and endocrine disrupting chemicals in an urban drinking water treatment plant. Water Res. 2014;51:266-276.

7. Kolpin DW, Furlong ET, Meyer MT, et al. Pharmecueticals, hormons, and other organic wastewater contaminants in U.S. streams, 1999-2000: A national reconnaissance. Environ. Sci. Technol. 2002;36:1202-1211.

8. Clara M, Kreuzinger N, Strenn B, Gans O, Kroiss H. The solids retention time - A suitable design parameter to evaluate the capacity of wastewater treatment plants to remove micropollutants. Water Res. 2005;39:97-106.

9. Guardabassi L, Petersen A, Olsen JE, Dalsgaard A. Antibiotic resistance in Acinetobacter spp. isolated from sewers receiving waste effluent from a hospital and a pharmaceutical plant. Appl. Environ. Microbiol. 1998;64:3499-3502.

10. Guardabassi L, Wong DMLF, Dalsgaard A. The effects of tertiary wastewater treatment on the prevalence of antimicrobial resistant bacteria. Water Res. 2002;36:1955-1964.

11. Crane M, Watts C, Boucard T. Chronic aquatic environmental risks from exposure to human pharmaceuticals. Sci. Total Environ. 2006;367:23-41.

12. Shirley J, Mandale S, Kochkodan V. Influence of solute concentration and dipole moment on the retention of uncharged molecules with nanofiltration. Desalination 2014;344:116-122.

13. Weng XD, Ji YL, Ma R, Zhao FY, An QF, Gao CJ. Superhydrophilic and antibacterial zwitterionic polyamide nanofiltration membranes for antibiotics separation. $J$. Membrane Sci. 2016;510:122-130.

14. Bengani P, Kou Y, Asatekin A. Zwitterionic copolymer self-assembly for fouling resistant, high flux membranes with size-based small molecule selectivity. J. Membrane Sci. 2015;493:755-765.

15. Shahmansouri A, Bellona C. Nanofiltration technology in water treatment and reuse: Applications and costs. Water Sci. Technol. 2015;71:309-319.
16. Moulik S, Vadthya P, Kalipatnapu YR, Chenna S, Sundergopal S. Production of fructose sugar from aqueous solutions: Nanofiltration performance and hydrodynamic analysis. J. Clean. Prod. 2015;92:44-53.

17. Elazhar F, Touir J, Elazhar M, et al. Techno-economic comparison of reverse osmosis and nanofiltration in desalination of a Moroccan brackish groundwater. Desalin. Water Treat. 2015;55:2471-2477.

18. Ravikumar YVL, Kalyani S, Satyanarayana SV, Sridhar S. Processing of pharmaceutical effluent condensate by nanofiltration and reverse osmosis membrane techniques. J. Taiwan Inst. Chem. Eng. 2014;45:50-56.

19. Song J, Zhang M, Figoli A, et al. Arsenic removal using a sulfonated poly (ether ether ketone) coated hollow fiber nanofiltration membrane. Environ. Sci. Water Res. Technol. 2015;1:839-845

20. Yang H, Wang X. Mechanism of removal of pharmaceuticals and personal care products by nanofiltration membranes. Desalin. Water Treat. 2015;53:2816-2824.

21. Teh CY, Budiman PM, Shak KPY, Wu TY. Recent advancement of coagulation-flocculation and its application in wastewater treatment. Ind. Eng. Chem. Res. 2016;55:4363-4389.

22. Suriyanon N, Permrungruang J, Kaosaiphun J, Wongrueng A, Ngamcharussrivichai C, Punyapalakul P. Selective adsorption mechanisms of antilipidemic and non-steroidal anti-inflammatory drug residues on functionalized silica-based porous materials in a mixed solute. Chemosphere 2015;136:222-231.

23. Lin YL, Lee CH. Elucidating the rejection mechanisms of PPCPs by nanofiltration and reverse osmosis membranes. Ind. Eng. Chem. Res. 2014;53:6798-6806.

24. Wu F, Feng L, Zhang L. Rejection prediction of isopropylantipyrine and antipyrine by nanofiltration membranes based on the Spiegler-Kedem-Katchalsky model. Desalination 2015;362:11-17

25. Feng G, Chu H, Dong B. Fouling effects of algogenic organic matters during nanofiltration of naproxen. Desalination 2014;350:69-78.

26. Yangali-Quintanilla V, Sadmani A, McConville M, Kennedy M, Amy G. Rejection of pharmaceutically active compounds and endocrine disrupting compounds by clean and fouled nanofiltration membranes. Water Res. 2009;43:2349-2362.

27. Nordvang RT, Luo J, Zeuner B, et al. Separation of $3^{\prime}$ -sialyllactose and lactose by nanofiltration: A trade-off between charge repulsion and pore swelling induced by high $\mathrm{pH}$. Sep. Purif. Technol. 2014;138:77-83.

28. Acero JL, Javier Benítez F, Real FJ, Rodriguez E. Influence of membrane, $\mathrm{pH}$ and water matrix properties on the retention of emerging contaminants by ultrafiltration and nanofiltration. Desalin. Water Treat. 2016;57:11685-11698.

29. Nghiem LD, Schäfer AI, Elimelech M. Pharmaceutical retention mechanisms by nanofiltration membranes. Environ. Sci. Technol. 2005;39:7698-7705.

30. Ang WL, Nordin D, Mohammad AW, Benamor A, Hilal N. Effect of membrane performance including fouling on cost optimization in brackish water desalination process. Chem. Eng. Res. Des. 2017;117:401-413.

31. Suárez A, Fernández P, Iglesias JR, Iglesias E, Riera FA. Cost 
assessment of membrane processes: A practical example in the dairy wastewater reclamation by reverse osmosis. $J$. Membrane Sci. 2015;493:389-402.

32. Sethi S, Wiesner MR. Cost modeling and estimation of crossflow membrane filtration processes. Environ. Eng. Sci. 2000;17: 61-79.

33. Xu L, Shahid S, Shen J, Emanuelsson E, Patterson DA. A wide range and high resolution one-filtration molecular weight cut-off method for aqueous based nanofiltration and ultrafiltration membranes. J. Membrane Sci. 2017;525:304-311.

34. Mahlangu TO, Schoutteten KVKM, D'Haese A, et al. Role of permeate flux and specific membrane-foulant-solute affinity interactions $(\Delta \mathrm{Gslm})$ in transport of trace organic solutes through fouled nanofiltration (NF) membranes. J. Membrane Sci. 2016;518:203-215. 